\title{
RELATIONSHIP MARKETING DAN SUASANA KAFE DALAM MENGOPTIMALKAN LOYALITAS PELANGGAN OASE Coffee
}

\author{
Relationship Marketing And Cafe Atmosphere In Optimizing Customer Loyalty Oase Coffee \\ Putri Reno Kemala Sari \\ ${ }^{1}$ Program Studi Manajemen, Fakultas Ekonomi dan Bisnis Universitas Teknologi Sumbawa \\ *) e- mail: putrenoks@gmail.com
}

\begin{abstract}
ABSTRAK
Penelitian ini bertujuan untuk mengetahui (1) Pengaruh Relationship Marketing Terhadap Loyalitas Pelanggan OASE Coffee, (2) Pengaruh Suasana Kafe Terhadap Loyalitas Pelanggan OASE Coffee, (3) Relationship Marketing dan Suasana Kafe Terhadap Loyalitas Pelanggan OASE Coffee. Penelitian ini termasuk penelitian kuantitatif asosiatif. Populasi dalam penelitian ini adalah seluruh pelanggan OASE Coffee. Metode pengambilan sampel menggunakan kriteria yakni merupakan pelanggan OASE Coffee dan telah melakukan kunjungan dan pembelian sebanyak tiga kali. Jenis data yakni data primer yang didapat dari hasil pengisian kuisioner dengan penilaian skala likert 4 poin. Uji prasyarat analisis meliputi uji normalitas, uji heteroskedastisitas dan uji multikolonieritas serta teknik analisis yang digunakan yakni analisis regresi linier berganda. Hasil penelitian ini menunjukan bahwa (1) Relationship marketing berpengaruh positif dan signifikan terhadap loyalitas pelanggan, (2) Suasana kafe berpengaruh positif dan signifikan terhadap loyalitas pelanggan OASE Coffee, (3) Relationship marketing dan suasana kafe secara bersama-sama berpengaruh positif dan signifikan terhadap loyalitas pelanggan OASE Coffee
\end{abstract}

Kata Kunci: Relationship marketing, suasana kafe, loyalitas pelanggan OASE Coffee

\section{Pendahuluan}

Kebiasaan minum kopi lekat dengan kehidupan manusia sejak berabad-abad yang lalu. Di era modern ini, minum kopi mempunyai banyak peran, tidak hanya sebagai sumber kenikmatan, tetapi juga sebagai media berkomunikasi. Konsumsi kopi diperkirakan akan meningkat di masa yang akan datang dikarenakan faktor budaya, kondisi ekonomi, perubahan selera dan perubahan gaya hidup. Zaman dan tradisi pun telah berubah, kaum muda mulai gemar minum kopi sebagai media pergaulan. "Fenomena ini terlihat dari dinamika pertumbuhan kedai kopi modern diberbagai tempat dengan fasilitas internet, dan audio-visual yang menarik minat pengunjung" (Mulato et,al, 2012:87).

Persaingan bisnis yang begitu ketat menyebabkan perusahan harus mampu memenuhi kebutuhan pelanggan agar dapat menciptakan loyalitas pelanggan. Loyalitas pelanggan sangat penting bagi perusahaan yang menjaga kelangsungan usahanya. Seperti yang dikemukakan Kotler (2009:153) "menciptakan hubungan yang kuat dan erat dengan pelanggan adalah mimpi semua pemasar dan hal ini sering menjadi kunci keberhasilan pemasaran jangka panjang". Pelanggan yang setia adalah mereka yang sangat puas dengan produk dan pelayanan tertentu, sehingga mempunyai antusiasme untuk memperkenalkan kepada siapa pun yang mereka kenal. Pelanggan yang loyal tersebut akan memperluas kesetiaan mereka pada produk atau jasa buatan produsen yang sama. Mencerminkan hal tersebut, strategi yang dapat dilakukan perusahaan dalam mempertahankan eksistensi perusahaan adalah memfokuskan diri dalam membina hubungan dengan pelanggan. Taleghani, et al, (2011) dalam jurnalnya " $A$ Conceptuality Approach to Relationship Marketing and Customers Loyalty to Banks" mengemukakan bahwa pemasaran hubungan merupakan strategi bisnis dengan kemajuan teknologi yang diperkuat melalui organisasiorganisasinya, menciptakan koneksi untuk membantu organisasi mengoptimalkan nilai yang diterima atas dasar pengolahan persepsi pelanggan.

memperkenalkan kepada siapa pun yang mereka kenal. Pelanggan yang loyal tersebut akan memperluas kesetiaan mereka pada produk atau jasa buatan produsen yang sama. Mencerminkan hal tersebut, strategi yang dapat dilakukan perusahaan dalam mempertahankan eksistensi perusahaan adalah 
memfokuskan diri dalam membina hubungan dengan pelanggan. Taleghani, et al, (2011) dalam jurnalnya "A Conceptuality Approach to Relationship Marketing and Customers Loyalty to Banks" mengemukakan bahwa pemasaran hubungan merupakan strategi bisnis dengan kemajuan teknologi yang diperkuat melalui organisasi- organisasinya, menciptakan koneksi untuk membantu organisasi mengoptimalkan nilai yang diterima atas dasar pengolahan persepsi pelanggan.

Relasi atau hubungan (Relationship Marketing) banyak dijumpai sebagai salah satu strategi penentu loyalitas pelanggan dalam hal ini pengunjung OASE Coffee. Dengan membangun hubungan yang baik dengan pelanggan maka keinginan pelanggan untuk melanjutkan hingga menuju kepada kesetiaan jangka panjang tidak diragukan lagi. "Relationship Marketing lebih banyak dijumpai dalam konteks pemasaran jasa dan pemasaran bisnis (business-to-business marketing)" (Tjiptono. 2011:299). Sejumlah riset menunjukan bahwa dua pilar utama relationship marketing adalah trust dan komitmen.

Dengan kata lain, pelanggan harus mempercayai pemasar dan selanjutnya berkomitmen padanya sebelum terjalin relasi yang saling menguntungkan dalam jangka panjang. Selanjutnya Tjiptono dan Chandra (2011: 330) "mengatakan bahwa relationship Marketing menawarkan strategi pemasaran untuk memperdalam hubungan dengan pelanggan, dalam hal ini pelanggan dipandang sebagai mitra yang harus terus dibina melalui pola win-win solution." Selain relationship marketing, strategi untuk mempertahankan pelanggan agar memperoleh kepuasan dan loyalitas yang tinggi adalah dengan menciptakan suasana kafe (store atmosphere) yang baik. Menurut Kotler (2005:89) "suasana kafe (store atmosphere) adalah suasana terencana yang sesuai dengan pasar sasarannya dan yang dapat menarik konsumen untuk membeli dan merasa puas". Store atmosphere menyebabkan rasa puas dan kesenangan tersendiri dihati konsumen.Kotler (2005:89) juga menjelaskan bahwa "store atmosphere tidak hanya dapat memberikan suasana lingkungan berbelanja yang menyenangkan saja tetapi juga dapat memberikan nilai tambah terhadap produk yang dijual".

Menurut Utami (2010:225) menjelaskan bahwa "suasana kafe merupakan kombinasi dari karakteristik fisik toko seperti arsitektur, tata letak, pencahayaan, panjang, warna, temperature, musik, aroma yang secara menyeluruh akan menciptakan citra yang baik dibenak konsumen". Suasana kafe merupakan salah satu faktor penting yang perlu diperhatikan. Semakin komunikatif suasana exterior kafe akan berpengaruh positif terhadap loyalitas pelanggan berkunjung ke kafe tersebut, dan semakin nyaman interior kafe akan membuat pelanggan betah berlama-lama di dalam kafe. Memuaskan keinginan pelanggan sendiri merupakan hal yang sulit, mengingat pelanggan yang merasa puas diharapkan akan berkunjung kembali, bahkan memberitahukan kepada orang lain, sehingga pada akhirnya dapat menempatkan pesaing di urutan paling rendah.

Di Sumbawa pun telah banyak kedai-kedai kopi yang berdiri hingga saat ini, termasuk salah satunya ialah OASE Coffee. OASE merupakan sebuah warung kopi komunitas yang menghimpun banyak orang. Buka sejak tahun 2016, OASE Coffee merupakan pelopor bagi kafekafe atau kedai-kedai yang ada di Kabupaten Sumbawa yang menjadikan kopi sebagai menu utamanya. OASE Coffee yang awalnya beralamat di Jl. Mawar No. 36 dan kini telah pindah lokasi di Jl. Kerato No.1, OASE Coffee bukan hanya berfokus pada aktivitas kopi saja, tetapi menjadi ruang edukasi dan interaksi berbagai komunitas di Sumbawa. Namun tidak jauh dari lokasi OASE berdiri, telah banyak kedai kopi lain yang mengusung konsep yang nyaris sama dengan OASE Coffee seperti MilkyBo, Tricia, D’Avalon, WRPM, dan Ruang Temu.

Tidak bisa dipungkiri, bahwa lingkungan bisnis akan terus berubah dengan cepat, persaingan baik domestik maupun global meningkat tajam dan dalam waktu yang sama tuntutan pelanggan pun akan terus berubah dan meningkat. Memuaskan keinginan pelanggan sendiri merupakan hal yang sulit, mengingat pelanggan yang merasa puas diharapkan akan berkunjung kembali, bahkan memberitahukan kepada orang lain sehingga akhirnya dapat menempatkan pesaing di urutan paling rendah. Berdasarkan latar belakang tersebut, maka penulis tertarik mengadakan penelitian yang berjudul

"Relationship Marketing dan Suasana Kafe dalam Mengoptimalkan Loyalitas Pelanggan OASE Coffee".

\section{Rumusan Masalah}

1) Bagaimana korelasi antara relationship marketing terhadap loyalitas pelanggan?

2) Bagaimana korelasi antara suasana kafe terhadap loyalitas pelanggan?

3) Bagaiman korelasi relationship marketing dan suasana kafe terhadap loyalitas pelanggan OASE Coffee?

\section{Metodologi Penelitian}

\section{Recencana Penelitian}

Jenis penelitian yang digunakan dalam penelitian ini adalah kuantitatif asosiatif. Tujuan dalam penelitian asosiatif ialah melihat pengaruh variabel independen terdahap variabel dependen. Variabel independen dalam penelitian ini adalah relationship marketing dan suasana kafe. Dan variabel dependennya adalah loyalitas pelanggan.

\section{Populasi dan Sampel}

Populasi yang digunakan dalam penelitian ini adalah seluruh pelanggan OASE Coffee. Pengambilan sampel dalam penelitian ini menggunakan metode purposive sampling. Kriteria sampel dalam penelitian ini ialah pelanggan OASE Coffee yang telah melakukan 
kunjungan dan pembelian sebangak tiga kali. Penentuan jumlah sampel ditentukan dengan mengguankan rumus sebagai berikut (Widiyanto, 2008: 59) :

$$
=\frac{Z^{\%}}{4(M o e)^{\%}}
$$

Keterangan :

$\mathrm{n}=$ ukuran sampel

$\mathrm{Z}=$ skor pada tingkat signifikansi tertentu (derajat leyakinan ditentukan $95 \%$ maka $\mathrm{Z}=1.96$

Moe $=$ Margin of error, tingkat kesalahan maksimum adalah $5 \%$

$n=96,04=97$

Dari hasil perhitungan rumus di atas, maka diperoleh jumlah sampel yang diteliti adalah sebesar 97, atau dilakukan pembulatan menjadi 100 responden yang dapat mewakili pelanggan OASE Coffee.

\section{Pengumpulan Data}

Metode pengumpulan data dalam penelitian ini metode kuesioner, teknik kuesioner merupakan teknik pengumpulan data yang dilakukan dengan cara memberikan seperangkat pertanyaan tertulis pada responden untuk dijawab Dalam penelitian ini, skala pengukuran yang digunakan adalah skala Likert, dengan menggunakan 4 skor interval.

\section{Analisis Data}

\section{Analisis dan Statistik Deskriptif}

Analisis deskriptif ini digunakan untuk menggambarkan distribusi frekuensi karakteristik responden yang dikelompokan berdasarkan usia, jenis kelamin dan pekerjaan dengan bantuan SPSS.

\section{Uji Asumsi Klasik}

Uji asumsi klasik bertujuan untuk mengetahui kondisi data yang dipergunakan dalam penelitian. Hal tersebut dilakukan agar diperoleh model analisis yang tepat. Menurut Sanusi (2011:135) model analisis regresi penelitian ini mensyaratkan uji asumsi terhadap data yang meliputi:

\section{Uji Normalitas Data}

Uji normalitas bertujuan untuk menguji apakah dalam model regrisi, variabel dependen dan independen keduanya mempunyai distribusi normal atau tidak. Uji normalitas data dalam penelitian ini menggunakan uji KolmogorovSmirnov. Kriteria pengujian dengan menggunakan uji dua arah, yaitu dengan membandingkan probabilitas yang diperoleh dengan taraf signifikan (a) 0,05. Jika p-value $>0,05$ maka data berdistribusi normal.

\section{Uji Multikolinearitas}

Uji ini bertujuan untuk menguji apakah pada model regresi ditemukan adanya korelasi antara variabel bebas. Model regresi yang baik seharusnya tidak terjadi korelasi antara variabel bebas. Jika variabel bebas saling berkorelasi, maka variabelvariabel ini tidak orthogonal.

"Variabel orthogonal adalah variabel bebas yang nilai korelasi antara sesama variabel bebas sama dengan nol" (Ghozali, 2009:95).

Untuk mendeteksinya yaitu dengan cara menganalisis tolerance dan variance inflation (VIF). Apabila nilai tolerance mendekati angka 1 dan VIF dibawah angka 10 maka bebas dari multikolinieritas

\section{Uji Heteroskedastisitas}

Uji ini bertujuan untuk menguji apakah dalam sebuah model regresi terjadi ketidaksamaan varian dari residual dari satu pengamatan $)_{\mathrm{k}}^{\circ}$ pengamatan yang lain. Jika varian dari residud $4 \%$ \% $\%$ pengamatan ke pengamatan yang lain tetap, maka disebut homokedastisitas, jika varian berbeda disebut heteroskedastisitas" (Ghozali, 2009:125). Dalam pengujian heteroskedastitas peneliti menggunakan metode Glejer. Kriteria terjadinya heteroskedastitas dalam suatu model regresi adalah jika signifikan kurang dari 0,05 atau terjadinya homokedastisitas.

\section{Analisis Regresi Berganda}

Analisis regresi berganda digunakan untuk mengetahui seberapa besar variabel bebas memengaruhi variabel terikat. Pada regresi berganda terdapat satu variabel terikat dan lebih dari satu variabel bebas. Dalam penelitian ini yang menjadi variabel terikatnya yaitu minat beli. Dan variabel bebasnya adalah harga, desain produk dan citra merek. Adapun bentuk regresi linear berganda dalam penelitian ini sebagai berikut :

$$
\mathrm{Y}=\mathrm{a}+\mathrm{b}_{1} \mathrm{X}_{1}+\mathrm{b}_{2} \mathrm{X}_{2}+\mathrm{e}
$$

\section{Pembahasan}

\section{Gambaran Umum Obyek Penelitian}

Oase Sumbawa merupakan perkumpulan pemuda dan pemudi Sumbawa yang mencoba meningkatkan potensipotensi daerah yang belum terangkat. Berdiri pada September 2014, terdiri dari delapan orang dari berbagai latar pendidikan yang beragam, mulai dari Sarjana Kehutanan (Bid. Lingkungan), Sarjana Kesehatan, Sarjana Perikanan, Sarjana Teknik Informatika, Sarjana Desain Grafis, Sarjana Geologi hingga Sarjana Gizi.

Sekretariat Oase Sumbawa berada di Jalan Mawar No.36 (depan SDN 7 Sumbawa) Kelurahan Bugis, Kabupaten Sumbawa dan kini telah berpindah lokasi ke Jalan Uner Iwes No.1 Kelurahan Unter Iwes. Pada tempat yang sama pula, Oase Sumbawa membuka coffee shop yang diberi nama OASE Coffee. OASE Coffee sendiri diharapkan dapat mengangkat kopi lokal Sumbawa seperti Tepal, Talagumung, Punik, Batu Rotok,dan Batu Dulang agar lebih dikenal baik oleh masyarakat Sumbawa sendiri maupun masyarakat luar Sumbawa.

\section{Karakteristik Responden}

Dalam penelitian ini, penulis melakukan penelitian pada pelanggan OASE Coffee dengan mengambil sampel sebanyak 100 orang. Berikut penulis sajikan mengenai jawaban responden atas dasar karakteristik: 


\section{Jenis Kelamin}

Karakteristik responden berdasarkan jenis kelamin yang diperoleh dalam penelitian ini, disajikan sebagai berikut:

Tabel 4.1 Krakteristik Jenis Kelamin Responden
\begin{tabular}{|l|l|l|l|}
\hline NO & Jenis kelamin & presentase \\
\hline 1 & Laki-laki & 72 & $72 \%$ \\
\hline 2 & Perempuan & 28 & $28 \%$ \\
\hline & Total & 100 & $100 \%$ \\
\hline
\end{tabular}

Sumber: Data Primer yang diolah 2018

Berdasarkan tabel 4.2 di atas menunjukan bahhwa responden berusia 18-28 tahun berjumlah $64 \%$ dan responden berusia 29-39 tahun berjumlah $36 \%$. Hal ini menunjukan responden paling banyak berasal dari usia 18-28 tahun.

\section{Pekerjaan}

Karakteristik responden berdasarkan pekerjaan yang diperoleh dalam penelitian ini, disajikan sebagai berikut:

Tabel 4.3 Jenis Pekerjaan Responden

\begin{tabular}{|l|l|l|l|}
\hline No & Jenis Pekerjaan & Jumlah & Persentase \\
\hline 1 & Pelajar/Mahasiswa & 20 & $20 \%$ \\
\hline 2 & PNS & 18 & $18 \%$ \\
\hline 3 & Pegawai Swasta & 31 & $31 \%$ \\
\hline 4 & Wiraswasta & 14 & $14 \%$ \\
\hline 5 & Lain-lain & 17 & $17 \%$ \\
\hline \multicolumn{2}{|l|}{ Total } & 100 & $100 \%$ \\
\hline
\end{tabular}

Sumber: Data Primer yang diolah 2018

Berdasarkan tabel 4.3. dapat dijelaskan bahwa pelajar/mahasiswa dengan jumlah $20 \%$, PNS dengan jumlah $18 \%$, pegawai swasta dengan jumlah $31 \%$, wiraswasta $14 \%$, dan lain - lain dengan jumlah $17 \%$.

\section{Jumlah Kunjungan dan Pembelian}

Karakteristik responden berdasarkan jumlah kunjungan dan pembelian yang diperoleh dalam penelitian ini, disajikan sebagai berikut:

Tabel 4.4 Jumlah Kunjungan dan Pembelian

\begin{tabular}{|c|c|c|c|}
\hline No & Kunjung & Jumlah & Presentase \\
\hline 1 & $3-6$ & 20 & $20 \%$ \\
\hline 2 & $7-10$ & 35 & 35 \\
\hline 3 & $>10$ & 31 & 37 \\
\hline \multicolumn{2}{|c|}{ Total } & 100 & $100 \%$ \\
\hline
\end{tabular}

Sumber: Data Primer yang diolah 2018

Berdasarkan tabel 4.4. dapat dijelaskan bahwa jumlah kunjungan dan pembelian 3-6 kali sebesar 20\%, 7-10 kali dengan jumlah 35\%, dan kunjungan dan pembelian $>10$ kali dengan jumlah $37 \%$.

\section{Uji Analsis Data \\ Uji Asumsi Klasik \\ Uji Normalitas}

Uji normalitas bertujuan untuk mengetahui normal atau tidaknya suatu distribusi data. Uji normalitas pada penelitian ini menggunakan bantuan program
SPSS Statisic 16 for windows dengan statistik One sample kolnogrov smirnov test. Pengukuran yang digunakan adalah membandingkan nilai Asymp. Sig (2Tailed) dengan nilai alpha yang ditentukan sebesar 5\%. Apabila nilai Asymp. Sig (2-Tailed) lebih besar dari 0,05 maka dapat disimpulkan bahwa data tersebut berdistribusi normal. Hasil uji normalitas adalah sebagai berikut:

\begin{tabular}{|l|lc|}
\hline \multicolumn{3}{|c|}{ One-Sample Kolmogorov-Smirnov Test } \\
\hline $\mathrm{N}$ & \multicolumn{2}{|l|}{ Unstandardize d Residual } \\
\hline Normal & Mean .0000000 \\
\hline Parameters & \\
\hline $\begin{array}{l}\text { Most } \\
\text { Extreme }\end{array}$ & Std. Deviation & 1.12125995 \\
\hline $\begin{array}{l}\text { Differences } \\
\text { Absolute }\end{array}$ & .067 \\
\hline $\begin{array}{l}\text { Kolmogorov- } \\
\text { Smirnov Z }\end{array}$ & Negative & .067 \\
\hline $\begin{array}{l}\text { Asymp. Sig. } \\
\text { (2-tailed) }\end{array}$ & &. .042 \\
\hline
\end{tabular}

Sumber: Data primer diolah 2018

Berdasarkan tabel 4.8 hasil uji normalitas di atas diperoleh hasil Asymp. Sig (2-tailed) sebesar 0,766 yang berarti lebih besar dari 0,05 , maka dapat disimpulkan bahwa data dalam penelitian ini mempunyai distribusi normal.

\section{Uji multikolonearitas}

Uji multikolinearitas bertujuan untuk mengetahui apakah terdapat gejala korelasi antar variabel independen lainnya. Model regresi yang baik seharusnya tidak terjadi korelasi di antara variabel bebas.Pemeriksaan untuk mendeteksi multikolinieritas dilakukan VIF (Variance Inflation Factor) yang dihitung dengan menggunakan SPSS Statisic 16 for windows. Hasil uji multikolinieritas disajikan dalam tabel berikut:

Tabel 4.6 Hasil Uji Multikolinearitas
\begin{tabular}{|l|l|l|l|}
\hline Variabel & $\begin{array}{l}\text { Toleran } \\
\text { ce }\end{array}$ & VIF & Keterangan \\
\hline Relationship & & & Tidak terjadi \\
\hline Marketing & .850 & 1.176 & multikolinearitas \\
\hline Suasana & & & suasana \\
\hline Kafe & .850 & 1.176 & multikolinearitas \\
\hline
\end{tabular}

Sumber: Data primer diolah 2018

Tabel 4.9 di atas menunjukan bahwa semua variabel bebas dari multikolinieritas karena nilai tolerance lebih besar dari 0,1 dan VIF lebih kecil dari 10.

\section{Uji Heteroskedastisitas}

Heteroskedesitas yakni menunjukan bahwa adanya varians variabel tidak sama untuk semua observasi. Model regresi yang baik adalah homoskedesitas bukan heteroskedastisitas. Untuk mendeteksi ada atau tidaknya heteroskedastisitas dalam penelitian ini menggunakan pengujian Glejer dengan syarat jika nilai Sig. diatas 0.05 maka tidak terjadi heteroskedastisitas. Dalam pengujian heteroskedastisitas menggunakan bantuan SPSS statistic for windows 16. Hasil uji heteroskedesitas dapat dilihat pada tabel berikut:

Tabel 4.7 Hasil Uji Heteroskedastisitas 


\begin{tabular}{|l|l|l|l|l|}
\hline $\begin{array}{l}\text { Unstandardized } \\
\text { Coefficients }\end{array}$ & \multicolumn{4}{|l|}{ Standardized Coefficients } \\
\hline $\mathrm{B}$ & Std. Error & Beta & $\mathrm{t}$ & Sig. \\
\hline 1.225 & .765 & & 1.602 & .112 \\
\hline-.014 & .037 & -.042 & -.386 & .700 \\
\hline-.004 & .026 & -.017 & -.158 & .875 \\
\hline
\end{tabular}

Dari tabel 4.10 diatas menunjukan bahwa nilai sig. dari relationship marketing (X1) sebesar 0.70 lebih besar dari 0.05 dan nilai sig. dari suasana kafe (X2) sebesar 0.875 lebih besar dari 0,05.Sehingga dapat diputuskan dari kedua variabel bebas dalam penelitian ini tidak ada indikasi heteroskedastisitas atau terjadinya homokedastisitas.

\section{Uji Linieritas}

Uji linieritas yakni menunjukan bahwa adanya pengaruh secara linier antara variabel bebas (X) dengan variabel terikat (Y). Uji ini biasanya digunakan sebagai prasyarat dalam analisis regresi linier. Dalam pengujian linieritas menggunakan bantuan SPSS statistic for windows 16. Dengan metode Test for Liniearity dengan taraf signifikan 0.05. Dua variabel dikatakan mempunyai hubungan secara linier jika nilai sig. (Linearity) < 0.05 .

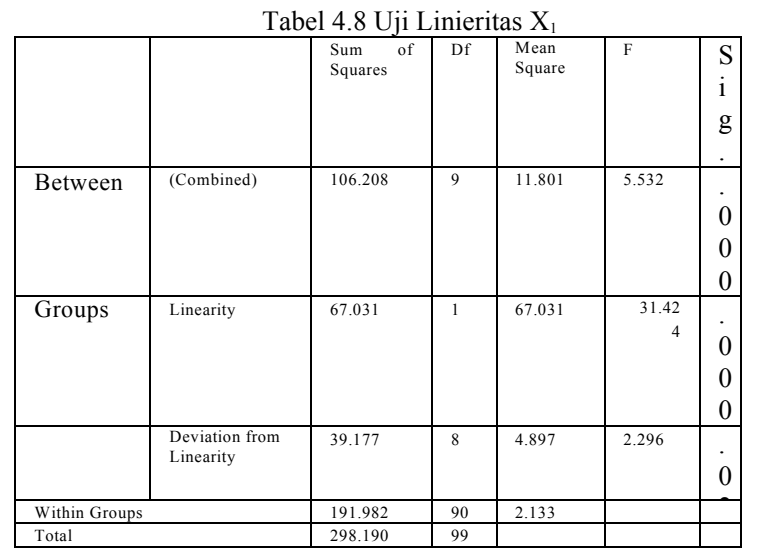

Diketahui pada tabel 4.11 bahwa nilai signifikansi pada Linearity sebesar 0.000 lebih kecil dari 0.05 , yang berarti bahwa terdapat hubungan secara linier antara relationship marketring dan loyalitas pelanggan.

Tabel 4.9 Uji Linearitas X
\begin{tabular}{|l|l|l|l|l|l|}
\hline Sum of Square & & & Mean & & \\
\hline $\begin{array}{l}\text { Between } \\
\text { (Combined) }\end{array}$ & s & df & Square & F & Sig. \\
\hline Groups & & 12 & .128 & 16.08 & .00 \\
& & & & & 0 \\
\hline Linearity & 1 & & & 4 & \\
\hline Deviation & & 161 & 161 & 151 & $\begin{array}{l}.00 \\
\end{array}$ \\
\hline from Linearity & 44.448 & 114 & 0413 & 794 & 0 \\
& & .09 & 09 & .2 & \\
\hline Within Groups & 92.649 & 87 & .065 & & \\
\hline Total & 298 & 0.19 & 99 & & \\
\hline
\end{tabular}

Diketahui pada tabel 4.12 bahwa nilai signifikansi pada Linearity sebesar 0.000 lebih kecil dari 0.05 , yang berarti bahwa terdapat hubungan secara linier antara suasana kafe dan loyalitas pelanggan.

Uji hipotesis.

Analisis regresi linier berganda.

Persamaan yang digunakan dalam penelitian ini adalah sebagai berikut:

$\mathrm{Y}=\mathrm{a}+\mathrm{b}_{1} \mathrm{X}_{1}+\mathrm{b}_{2} \mathrm{X}_{2}+\mathrm{e}$

Tabe 14.10 Hasil Analisis Regresi Liner

\begin{tabular}{|l|l|l|l|l|}
\hline $\begin{array}{l}\text { Unstandardized } \\
\text { Coefficients }\end{array}$ & $\begin{array}{l}\text { Standardized } \\
\text { Coefficients }\end{array}$ & & & \\
\hline Model & $\mathrm{B}$ & Error & Beta & sig \\
\hline 1 (Constant) & 1.229 & & -.399 & .691 \\
\hline Relationship & .060 & .223 & 3.138 & .002 \\
\hline Suasana Kafe & .042 & .649 & 9.119 & .000 \\
\hline
\end{tabular}

Berdasarkan tabel 4.9 maka persamaan regresinya sebagai berikut:

$\mathrm{Y}=-0,490+0,188 \mathrm{X} 1+0.383 \mathrm{X} 2+\mathrm{e}$ 


\section{Hasil Uji t}

Uji $t$ digunakan untuk menginterpretasikan pengaruh relationship marketing dan suasana kafe terhadapa loyalitas pelanggan. Hasil output tabel menunjukan bahwa nilai $\mathrm{t}$ hitung relationship marketing $\left(\mathrm{X}_{1}\right)$ sebesar 3,138 lebih besar dari tabel 1,960 dengan nilai signifikansi 0,002 lebih kecil dari 0,05 maka Ho ditolak dan Ha diterima, yang berarti relationship marketing berpengaruh signifikan terhadap loyalitas pelanggan. Diketahui nilai t hitung suasana kafe $\left(\mathrm{X}_{2}\right)$ sebesar 9.119 lebih besar dari t tabel 1,960 dengan nilai signifikansi sebesar 0,000 lebih kecil dari 0,05 maka Ho ditolak dan Ha diterima, yang berarti suasna kafe berpengaruh signifikan terhadap loyalitas pelanggan.

\section{Hasil uji koefisen determinasi (R square).}

Tabel 4.11 Hasil Uji Koefisien Determinasi

\begin{tabular}{|c|c|c|c|c|}
\hline Model & $\mathrm{R}$ & $\begin{array}{l}\mathrm{R} \\
\text { Square }\end{array}$ & $\begin{array}{l}\text { Adjusted R } \\
\text { Square }\end{array}$ & $\begin{array}{c}\text { Std. Error of } \\
\text { the Estimate }\end{array}$ \\
\hline 1 & .76 & .583 & .574 & 1.133 \\
\hline
\end{tabular}

Besarnya nilai koefisien determinasi ditunjukan pada tabel4.10 dengan nilai $\mathrm{R}$ square adalah 0,583. Hasil ini menunjukan bahwa pengaruh relationship marketing dan suasana kafe terhadapa loyalitas pelanggan sebesar $58,3 \%$ dan sisanya $41,7 \%$ dipengaruhi oleh faktor-faktor lain diluar penelitian ini seperti service quality.

\begin{tabular}{|c|c|l|l|l|l|}
\hline & Sum of Squares & df & $\begin{array}{l}\text { Mean } \\
\text { Square }\end{array}$ & F & sig \\
\hline $\begin{array}{c}1 \mathrm{Re} \\
\text { gres } \\
\text { sion }\end{array}$ & 173.725 & 2 & 86.862 & $\begin{array}{l}67 . \\
695\end{array}$ & 000 \\
\hline $\begin{array}{c}\text { Res } \\
\text { idu } \\
\text { al }\end{array}$ & 124.465 & 97 & 1.283 & & \\
\hline $\begin{array}{c}\text { Tot } \\
\text { al }\end{array}$ & 298 & .190 & 99 & & \\
\hline
\end{tabular}

Uji F dilakukan untuk mengetahui pengaruh variabel-variabel independen terhadap variabel dependen. Berdasarkan output pada tabel uji F, diketahui nilai $\mathrm{F}$ hitung 67,695 lebih besar dari $\mathrm{F}$ tabel 3,09 dengan nilai signifikansi 0,000 lebih kecil dari 0,05 maka dapat disimpulkan bahwa terdapat pengaruh signifikan relationship marketing dan suasana kafe secara bersama-sama terhadap loyalitas pelanggan.

\section{Kesimpulan dan \\ Saran Kesimpulan}

Berdasarkan hasil analisis dan pembahasan tentang pengaruh relationship marketing dan suasana kafe terhadap loyalitas pelanggan, maka dapat ditarik beberapa kesimpulan yaitu:

1) Terdapat pengaruh positif dan signifikan relationship marketing terhadap loyalitas pelanggan. Hal ini menunjukkan bahwa semakin baik relationship marketing OASE Coffee maka semakin tinggi pula loyalitas pelanggan OASE Coffee.

2) Terdapat pengaruh positif dan signifikan suasana kafe terhadap loyalitas pelanggan. Hal ini menunjukkan bahwa semakin baik suasana di OASE Coffee maka tingkat loyalitas pelanggan OASE Coffee semakin tinggi.

3) Terdapat pengaruh positif dan signifikan relationship marketing dan suasana kafe secara bersama-sama berpengaruh signifikan terhadap loyalitas pelanggan OASE Coffee. Hasil analisis menunjukkan bahwa relationship marketing dan suasana kafe berpengaruh positif dan signifikan terhadap loyalitas pelanggan. Hal ini pun

\section{DAFTAR PUSTAKA}

Anisa, Vita. (2016). Pengaruh Store Atmosphere Terhadap Kepuasn Pelanggan Café Little Wings Bandung. e-Proceeding of Applied Science: Vol.2, No.2. Universitas Telkom. Bandung.

Foster, Bob. (2008). Manajemen Ritel. Bandung: Alfabeta. Ghozali, Imam. (2009). Aplikasi Analisis Multivariate dengan Program SPSS. Semarang: UNDIP.

Griffin, Jill. (2005). Customer Loyalty: Menumbuhkan dan Mempertahankan Kesetiaan Pelanggan. Jakarta: Erlangga.

Hakim, Alif. (2016). Pengaruh Relationship Marketing Terhadap Loyalitas Pelanggan Melalui Kepuasan Pelanggan Pada Dongeng Kopi Jogja. Skripsi Universitas Negeri Yogyakarta.

Kotler, Philip. (2005). Manajemen Pemasaran. Jilid II. Jakarta: PT. Indeks.

Kotler, Philip dan Kevin Lane Keller. (2009). Manajemen Pemasaran. Edisi 13. Jakarta: Erlangga.

Mulato, Et Al,. 2012. Kopi, Seduhan Dan Kesehatan. Jember: Pusat Penelitian Kopi dan Kakao Indonesia.

Sanusi, Anwar. (2011). Metode Penelitian Bisnis: Cetakan Kelima, Jakarta: Salemba Empat..

Taleghani Et Al. (2011) Dalam Jurnalnya "A Conceptuality Approach To Relationship Marketing And Customers Loyalty To Banks" Dalam Journal Of Basic And Applied Scientific Research. Iran. Islamic Azad University.

Tjiptono, Fandy dan Gregorius Chandra. (2011). Service, Quality \& Satisfaction. Yogyakarta: ANDI OFFSET.

Utami, Christina Utami. (2010). Manajemen Ritel. Jakarta: Selemba Empat. 
JEBI Vol. 04, No.01, pp. 1-8 